[Profile] The Regenerative Culture of Extinction Rebellion: Self-care, People care, Planet care.

Emily Westwell ${ }^{\mathrm{a}}$ and Josh Bunting ${ }^{\mathrm{b}}$

a School of Social, Political and Global Studies, Keele University

(e.westwell@keele.ac.uk)

$b$ School of Social Sciences, University of Manchester

(joshua.bunting@manchester.ac.uk)

$11^{\text {th }}$ March 2020

Word Count: 2075 


\title{
[Profile] The Regenerative Culture of Extinction Rebellion: Self-care, People care, Planet care.
}

\author{
Key Words: \\ Extinction Rebellion, environmental activism, climate change
}

Just over a year ago on the streets of London, Extinction Rebellion (XR) launched itself as a mass environmental movement aiming to achieve systemic change through non-violent civil disobedience. Their public protests, occupying public space, holding symbolic actions such as die-ins and occupying transport links, have since spread to other countries, especially in Europe and Australia. XR UK have three core demands of the government: 1) it must 'tell the truth' about the global climate crisis and declare a climate emergency; 2) commit to net-zero carbon emissions by 2025; and 3) establish a citizens assembly to oversee the transition towards climate justice (see Extinction Rebellion, 2019).

While the actions and demands of Extinction Rebellion have received significant attention in the media, the internal culture of the movement is less commonly discussed. Within XR there is an explicit attempt to develop a cohesive internal culture, built on an ethics of care, termed 'regenerative culture'. Broadly speaking 'regenerative culture' can be understood as an evolving concept that challenges the 'fundamentally uncaring and destructive' relations of modern western society. XR draws inspiration from the work of Joanna Macy on 'active hope and sustainable activism', to embody or 'prefigure' the world they intend to build, one that recognises the interconnection between people and planet and cultivates a duty of care to protect it (Macy \& Johnstone, 2012).

This profile explores the concept and practice of regenerative culture drawing on our experience as activist researchers within Extinction Rebellion Manchester from August December 2019. Although regenerative culture is loosely defined and interpreted, we have understood it as having a foundation of self-care, people care and planet care. Consequently, our discussion is structured around these three principles. We suggest that regenerative culture informs the movement's ideology, organisation and strategy, and has the potential to be extremely subversive, fostering a new subjectivity for an ecologically sustainable society. However, tensions exist within XR's regenerative culture. Moreover, the regenerative culture is not commonly understood within the movement, or as pervasive as its proponents intend it to be. We highlight ongoing debates within XR and hope our observations inform its reflexive culture, as well as contributing to academic discussion of social movements. We begin by exploring self-care, followed by people care, and lastly, planet care.

\section{Self-care}

The first principle of regenerative culture, as XR activists have explained it to us, is self-care; positioned as the bedrock from which all other acts of care and consideration stem. Self-care 
centres on emotional and physical wellbeing, which in part has a strategic purpose to ensure movement longevity by preventing activist burnout. Meetings and workshops regularly begin with a check-in, which involves activists briefly expressing how they feel. This emphasis on wellbeing has antecedents in movements which have sought to link personal experience and activism, notably radical feminism, which has made space for emotional labour and feeling within movement strategy. In this way openly expressing emotion is a systematic practice within the regenerative ethos of XR. This extends to embracing despair and grief, which is best illustrated by XR's emotional debrief sessions and climate grief workshops. Activists we have spoken to often describe the necessity of facing this emotion and channelling it into action. This approach for mobilising inertia and despair is unusual for a social movement, as campaigns usually focus on hope and transformation, rather than using negative emotions as motivational tools. It seeks to challenge cognitive dissonance in relation to the planetary threat from climate change, through a culture of emotional connection that fosters compassionate and collaborative action.

These practices of emotional expression aim to build a culture of care and compassion that systematically produces and regenerates its activism. In XR Manchester, for example, 'check ins' at XR meetings and gatherings are a universal practice, but we found that self-care and regenerative principles more broadly were not fully embraced. While it is practiced, discussed and considered part of movement strategy at the centre of XR and in groups explicitly devoted to regenerative culture, it is not as widespread in the movement as its proponents would desire. The regenerative culture working group, with whom we spent most of our time, embodied regenerative principles in their own lives while actively working to create spaces for emotional connection, reflection and grounding in the movement, for instance, by discussing activist burnout and the need for self-compassion in meetings. Yet, to those new to XR and regenerative culture as a practice and ideology, it can be a barrier to their participation in the movement. As one prospective XR member described regenerative culture; 'it's difficult to put your finger on, but it feels like something spiritual and I am not sure I belong'. It is perhaps not surprising that those most open to regenerative culture were themselves more receptive to spiritual ideas or had a background or interest in psychotherapy. While we cannot comment beyond our experience of Manchester, we found that not all rebels, or prospective members, felt able to engage with regenerative culture in the same way, for some it can feel exclusive. This was evident when XR Manchester opened its weekly meeting after the April Rebellion to over 200 potential new rebels, with the playing of bird song and giving space for meditation. We feel this illustrates a tension in regenerative culture, between prefiguring a utopian ideal, and the more immediate task of movement building.

\section{People Care}

The second tenet of Regenerative Culture in Extinction Rebellion is "People Care". People Care is focused on relationships, both within the movement and outside of it. The most immediate manifestation of People Care to those arriving at an XR action is the presence of 
activists whose role is dedicated to wellbeing. This was evident in the Northern Rebellion (NRB) in September 2019, where a wellbeing hub was organised to support activists by providing emotional and physical support and check-ins for activists occupying roadblocks. Though this could involve just a friendly check-in, many activists expressed the value of these practices in sustaining morale. The highly organised and integral nature of wellbeing practices in XR's actions, demonstrates that XR believes it is crucial for undertaking a successful action. This can be seen further in affinity groups; the smallest organisational unit of XR. Adapted from movement structures used historically by Anarchist groups, they consist of approximately 8-12 individuals. In contrast to other affinity groups, XR's are structured with people care in mind: one member is designated the wellbeing officer and has a key role in facilitating action. Only a few members of each affinity group are designated as willing to be arrested, with the rest of the group fulfilling support roles, such as first aiders, arrestee support and de-escalation stewards.

As well as promoting wellbeing among activists during actions, Manchester XR was very keen to present a caring face to members of the public. Training sessions on non-violent communication and de-escalation were well attended before the NRB. Bystanders commented on the openness and friendliness of XR activists at the Northern Rebellion, with the action's atmosphere less like a protest and more like a country fair. This atmosphere was in part a result of XR's regenerative practices combined with a minimal police response to the NRB. Throughout the NRB workshops and meetings promoting regenerative practices were open to both activists and the public. Therefore, Manchester XR is keen to induct new members into the movement in a way that is consistent with regenerative principles.

While XR has attempted to expand the movement to achieve its aims and broaden its demographic, its internal culture does not necessarily appeal to all, and to some may seem exclusionary. For instance, its stance of respecting and collaborating with the police is often grounded in the idea that all human life must be respected. This approach can be seen both to enhance the movement's "worthiness" (Tilly \& Wood, 2012) in the eyes of the public, but also as a way of XR activists living their values. However, this stance could be alienating for some groups who experience the police as an oppressive institution. During our fieldwork we witnessed incidents where marginalised group's experiences of inequality and oppression were not fully recognised or addressed. Early in our fieldwork we observed that systemic issues such as racism were often individualised, rather than openly discussed collectively within the culture of Manchester XR. Yet, over the course of our research we have seen the development of collective discussion on these issues, as the Manchester group reflects on systemic inequality and how this can be challenged in the movements culture, tactics and strategy. This is not to suggest that this position is fully formed, nor is there a unanimous position on this within the movement. Rather, there is a growing critical awareness of these problems and the need for XR to consciously embody an alternative relational politics that confronts systemic inequality. 


\section{Planet Care}

Of the three areas of Regenerative Culture, planet care is explored the least in XR. This is perhaps due to it being the most intangible of an already amorphous set of ideals. Planet care aims to prefigure a new relational culture into an imagined future. This makes it quite different from self-care and people care, which are focused on movement building, constructing new subjectivities and developing tactics and strategy for action in the present. In meetings and conversations with Manchester activists an alternative future was rarely discussed, and when asked directly about how planet care would manifest on a societal scale there were few ideas about what this would look like or how it would come to fruition. In this sense, XR activists struggled to articulate or imagine the future they are working to create. This is not a challenge unique to XR, it is a challenge faced by social movements more generally, of balancing effective collective action in the present with mapping out an alternative for the future.

When we asked XR activists about how the world will be different if they are successful, they often defer the responsibility of imagining this to the citizen's assembly or talk about individuals making greener consumer choices. In fact, many XR activists we spoke to had little confidence in victory. As a result, there is a strain of apocalyptic thinking present in the movement. This is evident in its nihilistic artistic expressions and the popularity of Jem Bendell's pessimistic (2018) work, which suggests that societal collapse, due to climate breakdown, is inevitable. This worldview may stem from XR's apolitical stance. XR, presents itself as being 'Beyond Politics', based on the idea that climate change is a threat so significant, that all political differences should be put aside in order to solve it. It is particularly uncomfortable about being seen to engage with party politics. During the Northern Rebellion many XR activists we spoke to were unsure about how to deal with the arrival of people from a demonstration against the Conservative Government. Denying the political nature of what they are doing can isolate XR from potential allies who are also struggling against current political structures and makes it vulnerable to its very real enemies. In reality, XR is not "Beyond Politics", rather it is Beyond Politics as usual, and therefore against the political establishment that benefits from the status quo.

\section{Conclusion}

XR's regenerative culture has created a vibrant movement with a clear collective identity and supportive internal environment based on care. This culture is distinctive in emphasising the value of emotions, particularly negative emotions of grief and despair, which are embraced to incite action and accept the consequences of climate breakdown. However, regenerative culture faces the challenge of spreading beyond its core proponents to the fringes of the movement, where regenerative culture is not necessarily universally practiced or understood. Regenerative culture is also coming up against strategic obstacles, in how it resonates with those outside the movement, is more inclusive and is able to prefigure a sustainable future. 
For XR to mobilise effectively as a movement, its internal culture is integral, as it is for any social movement, and as such this culture must be strategic in what it cultivates and emphasises. There were signs towards the end of our fieldwork that XR Manchester activists were reflecting on the nature of regenerative culture and the movement more broadly; discussing social justice issues, considering movement strategy and learning from other movements. What we could be witnessing is the movement transforming through experience. We are keen to see the results of this process, and how regenerative culture adapts in the future.

\section{Acknowledgements:}

We are grateful to Extinction Rebellion Manchester for their willingness to take part in this research project, particularly the Regenerative Culture Working Group for welcoming us into the movement. We would also like to thank Brian Doherty for his editorial assistance and comments on previous versions of this paper.

\section{Bibliography:}

Bendall, Jem (2018) Deep Adaption: A Map for Navigating Climate Tragedy, Internal IFLAS Occasional Paper 2 - University of Cumbria, Unpublished.

Extinction Rebellion (2019) Our Demands, Extinction Rebellion UK, https://rebellion.earth/the-truth/demands/ (Accessed 01.11.2019)

Macy, Joanna; Johnstone, Chris., (2012) Active Hope: How to Face the Mess We're in Without Going Crazy, New World Library: Novato, CA

Tilly, Charles; Wood, Lesley, J., (2012) Social Movements 1768-2012. 3rd edn. Routledge: Abingdon 